\title{
Architectures of adaptive integration in large collaborative projects
}

\author{
$\underline{\text { Lois Wright Morton }}^{1}$, Sanford D. Eigenbrode ${ }^{2}$ and Timothy A. Martin ${ }^{3}$
}

\begin{abstract}
Collaborations to address complex societal problems associated with managing human-natural systems often require large teams comprised of scientists from multiple disciplines. For many such problems, large-scale, transdisciplinary projects whose members include scientists, stakeholders, and other professionals are necessary. The success of very large, transdisciplinary projects can be facilitated by attending to the diversity of types of collaboration that inevitably occur within them. As projects progress and evolve, the resulting dynamic collaborative heterogeneity within them constitutes architectures of adaptive integration (AAI). Management that acknowledges this dynamic and fosters and promotes awareness of it within a project can better facilitate the creativity and innovation required to address problems from a systems perspective. In successful large projects, AAI (1) functionally meets objectives and goals, (2) uses disciplinary expertise and concurrently bridges many disciplines, (3) has mechanisms to enable connection, (4) delineates boundaries to keep focus but retain flexibility, (5) continuously monitors and adapts, and (6) encourages project-wide awareness. These principles are illustrated using as case studies three large climate change and agriculture projects funded by the U.S. Department of Agriculture-National Institute of Food and Agriculture.
\end{abstract}

Key Words: architectures of adaptive integration; collaborative science; team science

\section{INTRODUCTION}

Generation of innovative science and its applications to address complex societal problems associated with managing humannatural systems requires research approaches that mirror the complexity of these systems. However, the architecture of large, multidisciplinary, multi-institutional, multiyear projects that undertake this requisite systems approach research is not well understood, despite increasing public and private funding and a growing discourse on transdisciplinarity and team science. In this synthesis paper, diverse conceptions of the processes and structures associated with conducting collaborative research are used to develop architectures of adaptive integration (AAI) for large-scale projects. In this context AAI is defined as the explicit and implicit dynamic structures and processes that characterize collaborations among heterogeneous groups of scientists and stakeholders working to address a shared problem affecting complex systems over time.

AAI offers a systems approach for reflexively examining the component parts and synergetic relationships of coupled humannatural systems to better understand adaptive responses to changing conditions. Following a synthesis of AAI traits, three large U.S. Department of Agriculture-National Institute for Food and Agriculture (USDA-NIFA) Coordinated Agricultural Projects (CAPs) focused on adaptation and mitigation of changing climate conditions are offered as examples of this architecture. The underlying premise of AAI is that projects that address complex systems may not necessarily conform homogeneously to a transdisciplinary ideal. Rather, we found that realizing the capacity of these projects requires (1) attention to the heterogeneous types of collaboration that can occur within them, (2) development of feedback mechanisms that encourage adaptive management that responds to changing conditions in the research and its applications, and (3) a purposefulness in incorporating the perspectives and expertise of academic and nonacademic participants to guide project structural adaptation.

\section{ARCHITECTURES OF ADAPTIVE INTEGRATION}

During the past decade the widely recognized need for science that can address complex systems problems has stimulated interest in cross-disciplinary collaboration and created a new set of terms and language: convergence of sciences (Sharp and Langer 2011), philosophical dialogue in collaborative science (Eigenbrode et al. 2007, Crowley et al. 2010, O'Rourke et al. 2013), collaborative productivity in scientific synthesis (Hampton and Parker 2011), and team science and transdisciplinarity (Max-Neef 2005, Stokols et al. 2008a, Lyall et al. 2014, Cooke and Hilton 2015). As part of this trend a literature has emerged that strives to delineate and quantify the diverse types of integration that can occur within scientific collaboration (Hampton and Parker 2011, Klein 2014). These schemata typically place scientific integration into hierarchical categories from disciplinary through multidisciplinary, pluridisciplinary, interdisciplinary, and transdisciplinary (e.g. Tress et al. 2004, Max-Neef 2005, Stokols et al. 2008a).

Although specifics vary, integration categories (Fig. 1) extend from those marked by relative independence of investigators and specialized disciplines to those that are deeply integrative, coordinated, and transformative; span disciplines; and include stakeholders throughout the effort (Tress et al. 2004), from question formulation through data gathering, interpretation, and applications. The last category, typically termed transdisciplinary, has been promoted as uniquely capable of and perhaps necessary for addressing society's most complex and difficult problems, such as those affecting interacting human and natural systems at different types of scale, i.e., time, space, and human institutions (Tress et al. 2004, Max-Neef 2005, Beachy 2010, Jackson et al. 2010, Hampton and Parker 2011, Hammond and Dube 2012, Lyall et al. 2014). Conceptually, transdisciplinarity extends beyond interdisciplinary integration to involve nonacademic stakeholders to address the gap that can exist between research and practical application by collaboratively generating knowledge (Lyall et al.2014). Effective integration uses a number of processes and structures to construct complex organization in ways that

${ }^{1}$ Department of Sociology, Iowa State University, ${ }^{2}$ Department of Plant, Soil and Entomological Sciences, University of Idaho, ${ }^{3}$ University of Florida 
enable researchers to create new scientific knowledge, involve stakeholders in generation and evaluation of new knowledge, and prepare new scientists to take on the multilayered complexity of coupled human-natural systems (Hampton and Parker 2011, Hammond and Dube 2012, Palmer 2012).

Fig. 1. Graphical representation of the concepts of disciplinary, multidisciplinary, participatory, interdisciplinary, and transdisciplinary research. Redrawn from Tress et al. (2004).

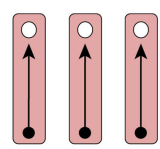

\section{Disciplinary}

Within one academic discipline

Disciplinary goal setting

- Development of new disciplinary knowledge

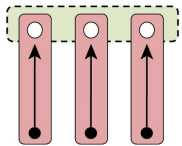

Multidisciplinary

- Multiple disciplines

- Multiple disciplinary goal setting under one thematic umbrella

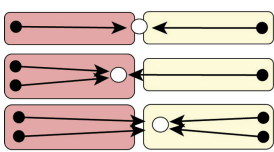

Participatory

Academic and nonacademic participants - Knowledge exchange without integration

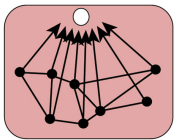

Interdisciplinary

Crosses disciplinary boundaries

- Development of integrated knowledge

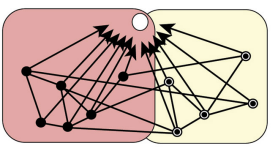

Transdisciplinary

- Crosses disciplinary and sectorial boundaries

- Common goal setting

- Develops integrated knowledge for science and society

- Stakeholder Participants

- Discipline

Goal, Shared Knowledge ${ }_{\text {Academic Knowledge }}$

szazz Thematic Umbrella $\rightleftarrows$ Conventional Knowledge

\section{Integration of knowledge}

Research in the natural and social sciences has evolved from observational, lab-based, and site-specific disciplinary sciences to examination of system relationships to highly connected interdisciplinary efforts that explicitly involve linkages among biogeophysical, human, and social systems (Collins et al. 2011). Research platforms that undertake to understand these continuously changing human-natural systems and their adaptive capacities must also continuously change and adapt to generate the variety of scientific data and stakeholder knowledge needed. These platforms are sources of capacity to integrate, synthesize, model, interpret, and apply the data at ever-increasing scales and complexity.

The AAI of any large collaborative project engaged in knowledge production of these systemic relationships has a variety of structures and processes to effectively integrate three types of knowledge: disciplinary, systems relationships, and stakeholder. The first type of knowledge is deep, specialized, disciplinary knowledge about system components (Palmer 2012) that is the basis of foundational science. The disciplinary approach uses tools, methods, procedures, concepts, and terms or language unique to that specific discipline (Tress et al. 2004). Disciplinespecific knowledge has been an essential building block of science. For example, rapidly expanding knowledge about cellular biology, biochemistry, and molecular biology results largely from disciplinary research. Thus, disciplinary specialization is essential to understanding the specific phenomena that together comprise systems (Johnson 2010, Hampton and Parker 2011).

The second type of knowledge concerns understanding whole systems and relationships among system components. This entails identifying the mechanisms and connections among individual parts that produce the emergent properties of the system and factors that drive and respond to change over time, e.g., temperature and precipitation combined with human management practices and their influences on soil moisture, emergence of crop disease, and the timing of plant growth, flowering, and seed set associated with yields (Johnson 2010, Collins et al. 2011). Systems research involves several disciplines combining theory development with a variety of research approaches ranging from primary data collection and comparative analyses to synthesis and modeling of primary and pre-existing data and findings. Theory development and testing that involve two or more disciplines are a negotiation over definitions and methods, and are characterized by agreement on what factors matter, what needs to be measured, how it needs to be measured, and who needs to be counted (Innes 1994). A wide variety of organizational structures and processes are possible to facilitate interactions among multiple disciplines to incorporate differing terminologies, methods and techniques, types of data, modeling, and synthesis (Tress et al. 2004, Jackson et al. 2010, Hammond and Dube 2012).

The third type of knowledge is of practitioners or stakeholders who evaluate disciplinary and systems knowledge against their personal experience and values to create their own perceptions of reality. This knowledge is grounded in everyday understandings and interpretations of the world as experienced. When scientific knowledge and ordinary stakeholder knowledge are given opportunities to closely interact, both are reshaped and changed (Innes 1994). This negotiated relationship is a valuable feedback mechanism that can lead to adaptions in the research design and new applications of science in the stakeholder community. Integration of stakeholder and scientific knowledge underpins the transdisciplinary research process, enabling collaborators to understand the connections and elements that comprise the entire system, as is implied by the Latin derivation of integration, "to make whole" (Klein 2012:284)

These three types of knowledge are complementary. Without disciplinary knowledge, essential processes cannot be known well enough to understand mechanisms and devise appropriate applications. Without systems understanding, specialized knowledge cannot be incorporated meaningfully to generate transformative insights and explanations relevant for the system as a whole. Without feedbacks between practitioners and the research enterprise, academic research may generate knowledge that is not directly useful for solving problems (Christensen et al. 1996). The structures and processes of an effective AAI must facilitate the synthesis and integration of knowledge specializations into layers of information that align with the 
complexity and diverse relationships of the phenomenon of interest to the collaborative effort.

\section{Typology of integration}

A widely used typology of integration ranging from disciplinary to transdisciplinary has been summarized by Tress et al. (2004) and is graphically presented in Figure 1. In this typology, transdisciplinary implies integration among scientists and stakeholders from project conception through execution, which differs from some other characterizations of this type of integration (Pohl et al. 2008a).

This typology, however, is inadequate to represent the range of collaborative complexity that occurs within a large project addressing human-natural systems. First, participants in crossdisciplinary collaboration (an inclusive term representing the entire typology of integration) may find that no one category of integration adequately describes their collaborative process. Second, very large projects such as those that have emerged to address issues like human responses to climate change, sustainability of natural resources, health of human populations and societies, and other systems issues require multiple nodes of collaboration, each with unique objectives and differing optimal levels of integration (Robertson and Swinton 2005, Reganold et al. 2011).

These projects can involve dozens or hundreds of participants from diverse disciplines (Hampton and Parker 2011, Hammond and Dube 2012). A hypothetical large, integrated project that includes subteams working together uses diverse types of collaboration. Some subteams may be mono-disciplinary collaborations, others may be strongly participatory, and still others may be interdisciplinary. As a whole, the project may be transdisciplinary with heterogeneous collaboration occurring throughout the project, with some subteams working closely with stakeholders and others pursuing specialized objectives or specific types of interdisciplinary integration. This collaborative architecture needs to be flexible and dynamic as conditions change (e.g., new scientific findings, feedback on applications from stakeholders) and as the project evolves and matures. For example, integration with stakeholders might reside primarily in one or a few subteams early in the project, but expand to others as the project develops. A project's AAI will tend to exhibit organic, dynamic, bottom-up fluidity, which is a signature of the collaborative process (e.g., Shaman et al. 2013). It is an emergent property that can be facilitated by project leadership using a variety of feedback mechanisms and management strategies. The AAI of each project is posited to be unique, consistent with Klein's (2012) first principle of integration: there is no universal formula for its success. However, a number of literatures suggest that some general AAI traits can be used to guide large project organization in effectively accomplishing the integration associated with transdisciplinarity.

\section{KEY ATTRIBUTES OF ARCHITECTURES OF ADAPTIVE INTEGRATION}

Based on the literature and examination of three large USDANIFA transdisciplinary projects, six key attributes of AAI are associated with the development and achievement of high levels of functioning in large team projects (Table 1). Multiple mixed methods were used to systematically gather data to track the formative development of these five-year USDA-NIFA projects and to evaluate early and intermediate outcomes from their inception in 2011. These include preproject, midproject, and postproject assessments (will occur in 2016) synthesized from surveys, focus groups, qualitative interviews, archival analyses of meeting recordings and action items, external evaluator observations and reports, social network analysis, and ethnography. Annual project renewals (Y1-Y5) to USDA-NIFA include summaries of these findings based on analyses generated by project directors and managers, project evaluators, and social scientists on the teams. However, more importantly, project directors and managers, core leadership, and entire teams have used these data sources for the last four years as feedback mechanisms to document and understand team processes to guide adaptive management in team development. Ongoing formative evaluation and team discussions have allowed project directors and managers to identify types and intensity of team integration throughout the projects, nodes within the projects where greater interdisciplinary exchanges would enhance research and application capacities, and ways to strengthen stakeholder involvement.

Table 1. Key attributes of architectures of adaptive integration (AAI) in large collaborative team projects

\begin{tabular}{|c|c|}
\hline 1. Goal-oriented & $\begin{array}{l}\text { Achieves overall project goals, objectives, and } \\
\text { deliverables }\end{array}$ \\
\hline $\begin{array}{l}\text { 2. Disciplinary and } \\
\text { cross-disciplinary } \\
\text { components }\end{array}$ & $\begin{array}{l}\text { Includes disciplinary subteams with deep } \\
\text { expertise in specific fields and cross-disciplinary } \\
\text { groups }\end{array}$ \\
\hline $\begin{array}{l}\text { 3. Mechanisms to } \\
\text { connect }\end{array}$ & $\begin{array}{l}\text { Uses a variety of virtual and face-to-face } \\
\text { mechanisms to facilitate communication and } \\
\text { functions }\end{array}$ \\
\hline $\begin{array}{l}\text { 4. Monitoring and } \\
\text { adaptation } \\
\text { processes }\end{array}$ & $\begin{array}{l}\text { Possesses mechanisms for monitoring } \\
\text { effectiveness and adjusting or adapting } \\
\text { architecture accordingly }\end{array}$ \\
\hline $\begin{array}{l}\text { 5. Defined } \\
\text { boundaries with } \\
\text { flexibility }\end{array}$ & $\begin{array}{l}\text { Creates an open environment to encourage } \\
\text { creativity and innovation while retaining project } \\
\text { vision and goals }\end{array}$ \\
\hline $\begin{array}{l}\text { 6. Awareness of } \\
\text { project architectures } \\
\text { of adaptive } \\
\text { integration (AAI) }\end{array}$ & $\begin{array}{l}\text { Encourages project-wide awareness of the AAI } \\
\text { to facilitate self-organization, feedback loops, } \\
\text { and adaptation }\end{array}$ \\
\hline
\end{tabular}

We discuss six AAI attributes grounded in the literature and apply them to large CAPs to illustrate the dynamic and evolving nature of these kind of projects. They are (1) goal-oriented structures, (2) disciplinary and cross-disciplinary components, (3) mechanisms to connect, (4) monitoring and adaptation processes, (5) defined boundaries with flexibility, and (6) awareness of project AAI (Table 1).

\section{Goal-oriented structures}

Publicly and privately funded large projects are expected to accomplish their proposed overarching vision and specified goals, objectives, and deliverables. The vision and supporting objectives drive project architecture and are continually used by project leadership and members to keep the work focused and to determine whether new opportunities contribute to or distract from the project purpose (Mattessich and Monsey 1992). Goals and objectives must be concrete, realistic, and attainable, as well 
as clear to all team members, to encourage joint spheres of activity and ensure unity of purpose (Bierly 1988, Mattessich and Monsey 1992, Schauppenlehner-Kloyber and Penker 2015). Agreement among the team on goals enables the integration and synthesis phases of the project (Bergmann et al. 2012, Cornell and Parker 2013).

Large teams typically are organized explicitly into subteams focused on specific project objectives that provide the building blocks of collaboration (Rhoten 2003, Hackett et al. 2008, Hampton and Parker 2011). They are represented in project organizational charts and provide the predetermined formal structure for organizing activities, for ensuring communication within the project, and for maintaining participant accountability. As large projects progress, however, gaps in the formal organization can become apparent, requiring spontaneous or deliberate formation and reformation of collaborative subgroups not originally included in the organizational structure (Pohl et al. 2008b, Stokols et al. 2008a, 2008b, Klein 2012). Guided by the goals of the project, the team structure evolves to include additional subgroups to enable delivery of results necessary for achieving the larger vision. The initial organizational charts of the three USDA-NIFA CAP projects (Fig. 2) illustrate the typical conceptual simplicity of project structures in their initial startup phase (Fig. 2a, 2c, 2e). In operation the realized project structure becomes more complex as additional subteams emerge and integration within the team occurs. This is represented by a more densely networked, dynamic organizational chart (Fig. 2b, 2d, 2f).

\section{Disciplinary and cross-disciplinary components}

Disciplinary scientists are the primary, fundamental units of cross-disciplinary teams (Sharp and Langer 2011, Palmer 2012), reflecting the current discipline-centered scientific training paradigm. Tress et al. (2004) in their typology of integration define disciplinarity as science within one discipline or subdiscipline that is oriented to the development of new, deeper knowledge and theory. Collaborative team success appears to hinge on the interplay between the disciplinary composition and network structure, according to Troster et al. (2014). Projects addressing issues that involve many disciplines must have collaborative structures to facilitate integration and synthesis of diverse disciplinary lenses (Pielke 2007, Strijbos 2010). Where these problems involve interacting human and natural systems, the integration must also include nonacademic knowledge of stakeholders (Pielke 2007, Bammer 2013, Dietz 2013). Centralized task networks help facilitate team performance through a structure of mutual dependences whereby groups of team members acquire work inputs, distribute work outputs to other team members, and integrate the project work flow (Troster et al. 2014).

Participants in large cross-disciplinary projects must deliberately work to understand the languages of other disciplines. "Strong" transdisciplinarity as described by Max-Neef (2005) creates a distinct, emergent, synthetic, and shared conceptual reality and language that draws upon the perspectives of its contributing disciplines. In practice this ideal may not be achievable or necessary for success by large projects involving dozens of scientists and many disciplines that exist over a relatively short time. Nonetheless, pragmatic evolution of a shared language from Babel through pidgin to Creole (Blackwell and Good 2008) can improve understanding and effectively facilitate integration across the disciplines as a project evolves.

A manifestation of spontaneous creativity and adaptive integration in the USDA-NIFA CAP projects has been the emergence of ad hoc workgroups not specifically delineated in original organizational charts but arising to address newly identified tasks and goals (Fig. 2). Some of these ad hoc workgroups are disciplinary, but most cross disciplines to address issues such as climate and cropping systems modeling, integrating regional economic models with climate projection and socioeconomic scenarios, integrating climate projections and biotic models, monitoring greenhouse gas emissions from controlled agronomic experiments, and assessing nitrogen loss via water transport or carbon retention in soil. These ad hoc workgroups represent emergent adaptive architecture that builds collaborative environments.

\section{Mechanisms to connect}

Although most participants in large collaborative projects bring a commitment to work closely with a diversity of scientists and stakeholders, few have the experience and skills for doing so. Traditional metrics of academic excellence used for recognition and promotion emphasize individual accomplishments and single or first author publication of scientific findings. Thus, people who are academically successful tend not to collaborate or develop the team skills needed to conduct transdisciplinary research. Further, those new to collaboration on large-scale projects are often unprepared for the additional time required to develop new skills and sustain cross-disciplinary effort. The project must be purposeful in using a variety of mechanisms to connect participants, impart collaborative skills, facilitate learning, build trust, and foster a culture that supports and rewards the additional effort and risk taking involved. Further, actionable crossdisciplinary science requires engagement of stakeholders to ensure research is compatible with social norms, behaviors, and governance structures (Wright Morton and Brown 2011, Palmer 2012). Climate-related projects, for example, contend with disparities between scientific understanding of climate, agriculture, and forestry and the knowledge, experiences, and beliefs of farmers, foresters, and other stakeholders who are the intended beneficiaries of the research (Lubell et al. 2011, Arbuckle et al. 2013, 2014, Prokopy et al. 2015).

There are three key structural challenges in enabling effective connections and integration among cross-disciplinary project participants: (1) how to link different conceptual frameworks to allow creative cross-disciplinary synthesis from problem formulation to execution and application, (2) how to use technology to enable relationship building and effective collaboration across space and time, and (3) how to involve stakeholders to ensure project science is actionable. Schauppenlehner-Kloyber and Penker (2015) suggest that participatory group processes that catalyze social learning help projects move toward transdisciplinary problem solving. The team must recognize and be willing to learn from the diversity of assumptions, approaches, scientific vernaculars, and methods within the collaborative project (Eigenbrode et al. 2007, Pennington 2008, Sharp and Langer 2011).

Explicit, mutually agreed upon rules of engagement can be implemented concerning expectations for collaborative 
Fig. 2. Graphical representation of the adaptive architectures of integration for three U.S. Department of Agriculture-National Institute of Food and Agriculture (USDA-NIFA) Coordinated Agricultural Projects. Panels a and b, Pine Integrated Network: Education, Mitigation and Adaptation Project (PINEMAP); panels c and d, Regional Approaches to Climate Change for Pacific Northwest Agriculture (REACCH-PNA); panels e and f, Cropping Systems Coordinated Agricultural Project: Climate Change, Mitigation, and Adaptation in Corn-based Cropping Systems (CSCAP). Illustrated are the collaborative structures of these projects at conception in spring 2011 and as of March 2014. Each project is visualized as a combination of disciplinary, multidisciplinary, participatory, and transdisciplinary effort. As the projects progress, their collaborative architectures become more complex, incorporating ad hoc teams or working groups to address emerging challenges and opportunities. These working groups are a mix of interdisciplinary or transdisciplinary efforts. Graphical conventions are as in Figure 1. AEZ indicates agroecological zone; LCA, life cycle analysis.

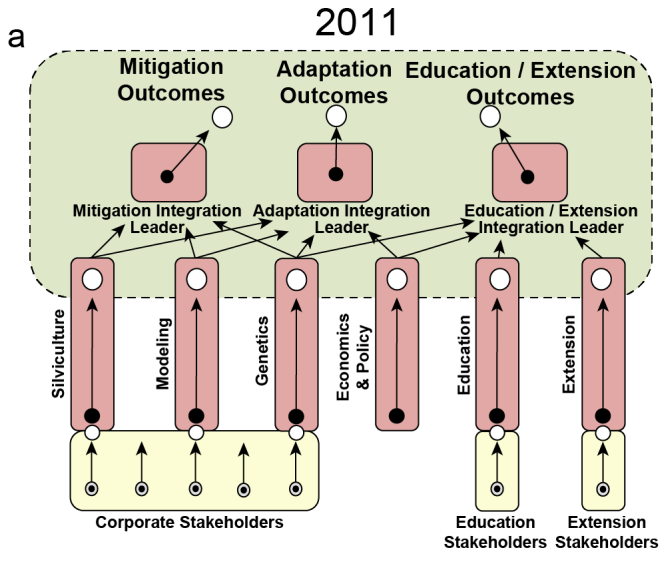

C

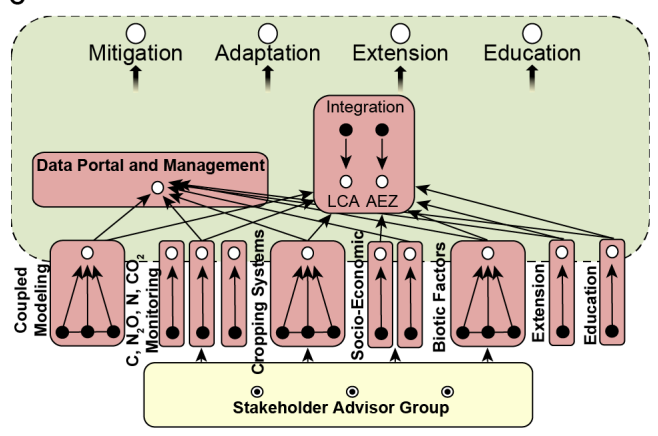

e

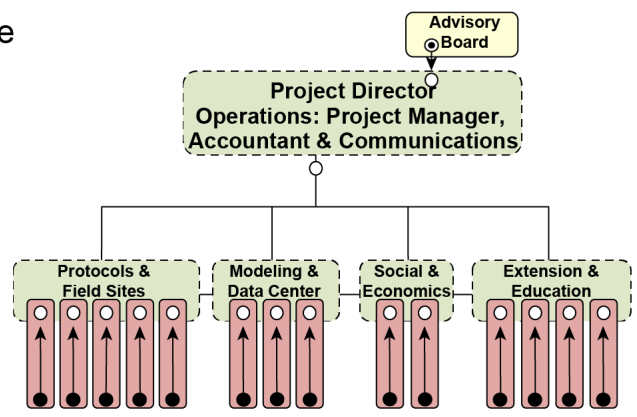

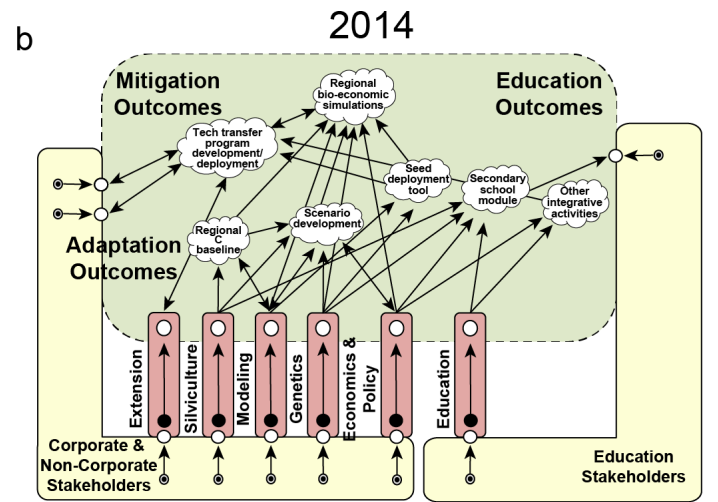

d
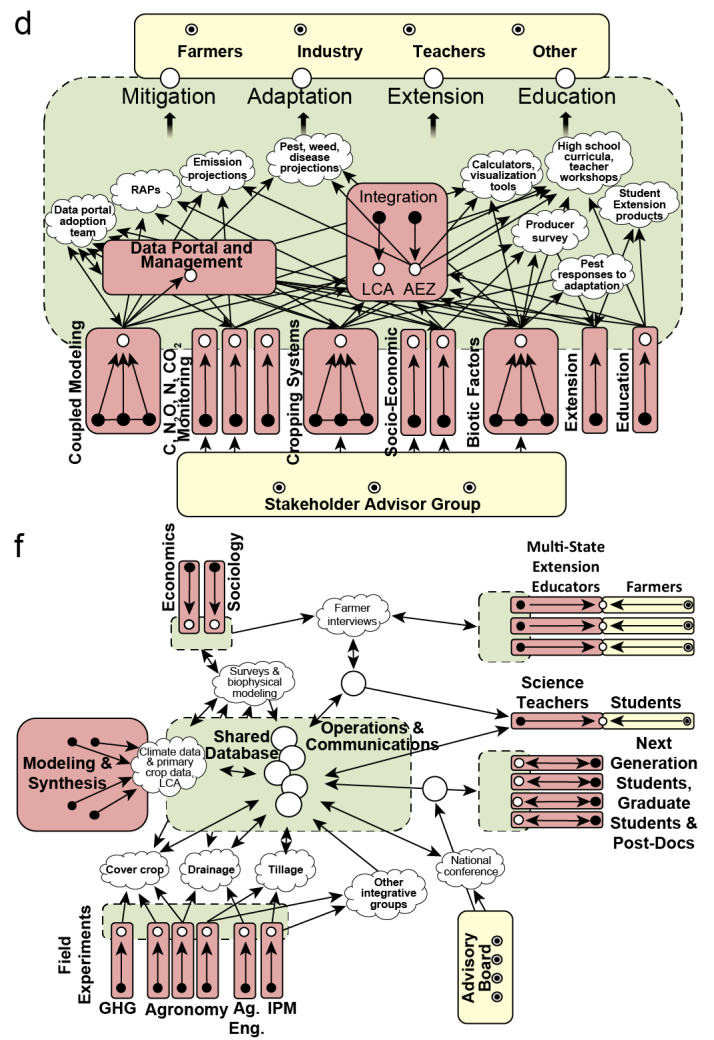

$\odot$ Stakeholder Participants
Discipline
$\bigcirc$ Goal, Shared Knowledge
Academic Knowledge Thematic Umbrella
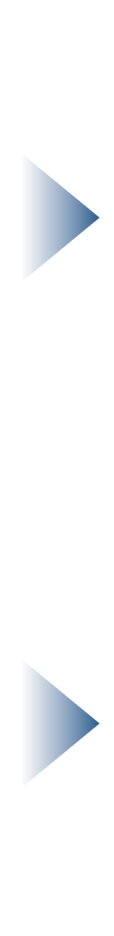

Ad-Hoc Team or Working Group 
comportment, strategies for negotiating differences and arriving at agreement in teams and across the project, clear expectations for data management, and policy and intellectual contributions to publications and other products. Such rules help form the basis for a shared culture, can keep the project in focus, reduce uncertainty, and encourage and reward collaborative engagement.

Multi-institutional teams by definition are not spatially colocated and so immediately face challenges to communication and team building. The importance of face-to-face social interactions for rapid communication of ideas and information, building instrumental trust, i.e., trust associated with judgment of risk (Slovic 2000), and diffusing conflict (Hampton and Parker 2011, Rubin and Fornari 2011) are well recognized. A number of studies find that face-to-face group meetings are most effective in building team cohesiveness, developing trust, and increasing communication efficiency to accelerate idea generation (Hackett et al. 2008, Hampton and Parker 2011, Rhoten 2003). Hampton and Parker (2011) report that the number of face-to-face meetings among team members is the strongest predictor of working group productivity and scientific impact, even when project total length of time is controlled for.

Approaches to address this challenge within virtual or semivirtual organizations include combining use of virtual collaborative tools such as standard email and telephone, specialized listservs, telephone conferencing, and virtual visual-audio technologies to allow the entire team and subteams to meet regularly. Awareness, good humor, and tolerance for the limitations of virtual communication and the adoption of best practices to maximize the quality of these interactions are required (Bazarova and Walther 2009, Johnson et al. 2009, Wasson 2012).

Mechanisms to involve stakeholders are varied and depend upon the type of project. Methods implemented to different degrees by the three USDA-NIFA CAP projects include (1) integrating stakeholders in all stages of the research; (2) providing opportunities for stakeholders to discuss a particular topic or project theme, with feedback loops so stakeholders can see how their ideas are implemented; (3) field days and themed presentations directed to public stakeholder meetings; (4) computer software or web tools that enable stakeholder interaction with the project and with one another in a virtual community; and (5) establishment of stakeholder advisory group that has an ongoing expectation of participation and engagement.

\section{Monitoring and adaptation processes}

Although all well-planned projects begin with an explicit organizational or functional structure, the size and complexity of large projects and their tasks preclude anticipating how project needs and interactions will evolve as work progresses, and the relative importance of multiple collaborative goals often shifts over time (Stokols et al. 2008b). Thus, processes are needed that allow the adjustment or adaptation of project structure given incomplete knowledge of future needs. This is analogous to the situation for environmental management scenarios where multiple interacting environmental and biological factors confound prediction of system responses to management inputs yet must be acted on despite imperfect knowledge (Holling 1978, Walters 1986, NRC 2010, Pryor 2013). Adaptive management is an iterative process, with monitoring following implementation of the initial management plan, periodic assessment of outputs and outcomes, and associated adjustment of management actions as knowledge of the system response improves (Rist et al. 2013). The original formulations of adaptive management (Holling 1978, Walters 1986) incorporated mechanisms for feedback from stakeholders (Rist et al. 2013). Adaptive governance, an important social construct on which adaptive management rests, is key to connecting efforts across multiple organizational levels and enables self-organized teams to draw on many knowledge sources to achieve common goals (Folke et al. 2005). All of these features of adaptive management are appropriate for large crossdisciplinary projects.

Monitoring tools to inform the formative development of projects include surveys of project participants, in-person structured conversations with team members, observational notes on workgroup meetings by leadership and external evaluators, analyses of archived meeting activities and actions (e.g., publications, presentations), quarterly progress reports, ethnography, input from stakeholder groups, and social network analysis based on surveys of participants about the nature of their interactions with one another.

\section{Defined boundaries with flexibility}

Strategic and organizational flexibility is central to a group's ability to adapt to both anticipated and unforeseen change (Evans 1991). The variety of integrating networks and partnerships is not static but transitions among different types and scales of activities and connectivity as part of the fluid creative process of pursuing and applying science creatively (Johnson 2010). This fluidity can be stimulated by purposeful formal and informal opportunities for conversation and information exchange that includes "spill over" or "leakage" from one network or subgroup to another both within and external to the organization. Flexibility in complex teams has been empirically linked to effectiveness (McComb et al. 2007) and incorporates both proactive elements, i.e., planning for future change, and reactive elements, i.e., responses to unpredicted events (Evans 1991). It is critical, therefore, that team members remain flexible with regard to team strategy and organization for an adaptive approach to be effective (Stokols et al. 2008b).

The fluidity of AAI calls for an organizational structure that has flexibility but is bounded by and stays focused on its goals. One way to incentivize flexibility and innovation within a large structure is to encourage what Wheatley (1999) calls "selforganization" within the project and subgroups. Self-organization means that the project director and manager do not make all the decisions and then distribute them to team members to do, but rather assume that each member knows well a segment of the science and is expected to contribute as they see what needs to be done. Hampton and Parker (2011) call this a laissez-faire management approach, which allows working groups autonomy and flexibility to organize according to what they are charged to accomplish. This structure tacitly acknowledges that each participant brings distinct types of knowledge, management and communication skills, and personal networks and relationships, and is expected to contribute them to the benefit of building the next layers of scientific innovation. Troster et al. (2014) found that moderately centralized task networks facilitate team performance. Thus, the role of leadership is to maintain the focus 
and direction of the work "while allowing flexibility to capitalize on the serendipitous, potentially transformative ideas that emerge" (Hampton and Parker 2011:908). When this flexibility with boundaries approach is coupled with well-designed monitoring and feedback processes, networked subteams increase their probability of contributing to project outcomes.

\section{Awareness of project AAI}

Project-wide awareness of the AAI serves to encourage team selforganization and shared responsibility for progress toward project goals and appropriate adaptive actions. As individual team members better understand the evolving structure, where they fit individually and as members of subteams and the whole team, they have opportunities and power to reinforce and expand on what is working and set aside those efforts that distract or seem peripheral to the project as a whole. When monitoring findings are shared widely beyond the project director, the operations team, and leadership, they become feedback mechanisms that can increase the accountability for subgroup productivity as well as the overall team. A project's AAI may not be apparent to project participants unless it is explicitly and regularly discussed among team members. Once the evolving structure and processes are understood throughout the team, efficiency and effectiveness are more likely to occur. Awareness of such collaborative structures in very large projects can also help leadership and participants to realize the enormous potential of collaboration and achieve results proportional to the public and private investment that is being made in support of such projects. Further, this awareness increases capacity of individual scientists to lead and/or more effectively contribute to the success of future collaborative projects.

In the following section, three large, USDA-NIFA funded CAPs are presented as case studies to illustrate the diversity of AAI that can arise as scientists and stakeholders organize to address societal issues. This analysis also offers evidence that these six AAI attributes can help cultivate and enhance team awareness and capacity to accomplish cross-disciplinary, large-scale, outcomes-based collaboration.

\section{TRANSDISCIPLINARY PROJECTS}

\section{Climate, agriculture, and forestry CAPs}

Scientific concern over climate change and variability and the interconnectedness of climate, the natural environment, and human society has led to a number of public and private investments in transdisciplinary projects to encourage innovation and cross-cutting scientific ideas (Shaman et al. 2013). The USDA-NIFA CAPs well demonstrate the emergent and dynamic collaborative structures of large integrated projects that connect the growing multidisciplinary field of climate science and the wellestablished but diverse fields of agriculture and forestry, which consist of many biophysical and social science subdisciplines. The USDA-NIFA CAPs reflect the land grant university system's three-part mission of research, education, and extension/ outreach. These competitively funded projects are part of the response by NIFA to the challenges related to climate change affecting U.S. agriculture and forestry.

Current and projected changes in the severity and timing of weather events underscore the vulnerability of agriculture and forestry to climate change (Walthall et al. 2012). Climate models agree on global warming trends, but there is less certainty about regional and local weather projections and impacts. Localized spatial variations present a big gap in knowledge about the contributions of different cropping and forestry systems to greenhouse gas, as well as the vulnerabilities and adaptation capacities of these systems under extreme climate conditions such as drought, flooding, heat, and windstorms. Research undertaken to address these complex questions benefits from multidirectional exchanges (Palmer 2012) among researchers, foresters, and farmers. These projects have goals to prepare the next generation of scientists to work collaboratively and to carry forward the coupled human-natural system science necessary to improve adaptation to climate change and mitigation of atmospheric greenhouse gas through carbon and nitrogen management in agroecosystems.

In 2011 USDA-NIFA funded, through their competitive grants program, three climate CAPs totaling $\$ 60$ million as proposed by 115 principal investigators representing 27 institutions (Eigenbrode et al. 2014). These five-year projects have transdisciplinary goals, integrating diverse disciplines within the biogeophysical and human sciences. They have extension and educational components, and are charged with initiating changes in knowledge and human behavior that can improve mitigation and adaptation to climate change across an extensive private sector. By necessity, they must connect academic and nonacademic knowledge in multidirectional ways. NIFA's charge to these projects was to produce quantifiable outcomes, with focus on reductions in $\mathrm{CO}_{2}$ and $\mathrm{N}_{2} \mathrm{O}$ emissions, increased carbon retention and sequestration, reduced or more efficient use of nitrogen fertilizers, attention to the water cycle, and increased resilience to climate change. The three CAPs have adopted a collaborative approach to managing the three projects consistent with a shared charge and similar challenges in meeting it. Project leadership early on realized that the explicit organization of their projects as proposed in 2011 organizational charts (Fig. 2a, c, e) was an inadequate representation of the team science that they were attempting to foster and that was taking place in the projects. The organizational charts were flat, static, and hierarchical, whereas the project activities were multidimensional, dynamic, and adaptive. The AAI attributes we propose were distilled from analyses of these three projects and are visually represented in Figure 2.

\section{Pine Integrated Network: Education, Mitigation and Adaptation} Project

The original 2011 organization structure of Pine Integrated Network: Education, Mitigation and Adaptation Project (PINEMAP) consisted of six disciplinary teams arranged in "parallel," each with two leaders from separate institutions (Fig. 2a). Integration leaders were assigned with the responsibility to engage and guide the disciplinary teams in carrying out the interdisciplinary collaboration necessary to achieve PINEMAP's transdisciplinary deliverables. As the project progressed, it became clear that this structure was too top down and placed too much responsibility on the individual integration leaders. The integration leader construct was supplemented with ad hoc groupings of scientists from multiple disciplines, each based on a particular interdisciplinary activity or integration platform necessary for making progress toward overall project goals. This decentralized structure (Fig. 2b) has been effective at facilitating 
simultaneous progress on multiple interdisciplinary activities within PINEMAP. There was also a shift in structure, which better accommodates the role of stakeholders in the project. In its original formulation, stakeholder engagement was structured primarily as an input associated with pre-existing corporate landowner-university forestry research cooperatives (Fox et al. 2007), the cooperative extension system, noncorporate landowners, and environmental education stakeholder groups. As PINEMAP moved toward implementing applied outcomes, the project more explicitly specified the two-way interaction with stakeholders necessary to achieve the project's mitigation, adaptation, and education goals, and combined many efforts targeted at corporate and noncorporate landowners. The extension efforts were also moved to a more central and connected node in the project structure. Taken together, these stakeholderand outreach-related structural changes enable PINEMAP to more efficiently engage in the iterative communication with stakeholder groups necessary to achieve the project's outcomes.

\section{Regional Approaches to Climate Change for Pacific Northwest Agriculture}

Regional Approaches to Climate Change for Pacific Northwest Agriculture (REACCH-PNA) was structured in 2011 with nine objectives: five scientific, disciplinary objectives; two objectives focused on education and extension; and two supporting objectives, one focused on cyber infrastructure and one integrating objective that included two cross-cutting, integrating teams: Life Cycle Analysis and Agroecological Zonation (Fig. 2c). Each team had a designated lead principal investigator. It was envisioned that integration would occur as needed among the teams, especially via the shared cyber infrastructure, extension, and education activities. This structure has remained in place and the objective teams have functioned effectively, but it has also generated 10 emergent, ad hoc working groups that are addressing various cross-cutting activities within the project (Fig. 2d). Some of these working groups will likely continue for project duration (e.g., student extension products), and others active at this point may dissipate as their tasks are completed. New ad hoc groups are still anticipated, e.g., one linking biotic factors with integrated modeling. Collaborations have also emerged between REACCHPNA principal investigators and students and those involved in a NIFA-sponsored project on Site Specific Climate Friendly Farming (USDA-NIFA \#2011-67003-30341). The latter project is building capacity for fine-scale, i.e., within-field, monitoring of greenhouse gas and soil nitrogen and carbon that is complementary to the region-wide efforts of REACCH-PNA (not shown in Fig. 2).

\section{Climate and Corn-based Cropping Systems}

The original 2011 organizational structure of the Cropping Systems Coordinated Agricultural Project: Climate Change, Mitigation, and Adaptation in Corn-based Cropping Systems (CSCAP) project consisted of a linear configuration of five objectives, primarily organized around disciplinary sciences under the direction of a project director and a project manager who coordinated the work of the team (Fig. 2e). Extension and education were combined into a single objective. One of the first adaptations to the project structure was the separation of extension and education into two distinct stakeholder groups and a deliberate effort to deepen the climate and agriculture scientific knowledge within each group. In year 1, deep disciplinary efforts by objective established protocols for standardization of experimental site data for the central database, inventoried the large variety of models used by different disciplines, and developed the theoretical framework for a social-economic survey instrument for farmers. As the project evolved, the central database facilitated project integration by providing a common focus among engineers, agronomic and social scientists gathering primary data, and a number of scientists who used public data sets associated with water, climate, and agricultural land management practices for modeling. By the third year of the project, the team had self-organized to create a variety of ad hoc interdisciplinary and multidisciplinary groups (Fig. 2f) such as drainage, cover crops, tillage, soybean, national conference, and social-economic climate research with another NIFA project, Useful to Usable (USDA-NIFA \#2011-68002-30220; not shown in Fig. 2). The project transdisciplinary goal of integration and synthesis is continually reinforced throughout the whole team and subgroups using a variety of communication strategies and includes active engagement among stakeholders and the diversity of multidisciplinary groups. Project graduate students, in particular, quickly grasped the value of the transdisciplinary concept and are working hard experimenting with ways to put it in action.

\section{KNOWLEDGE PRODUCTION AND APPLICATION}

Twenty-first century science will be marked by synthesis and integration of sciences (Hampton and Parker 2011). The challenge is to scale up and integrate from cells to organism to the larger ecosystem incorporating human institutions and changes across time (Jackson et al. 2010). This often entails scaling up the science to large, transdisciplinary efforts involving many scientists in multiple disciplines and the stakeholders. Transdisciplinary teams offer opportunities to construct a synthesis of knowledge systems that can develop actionable science to address socially relevant issues affecting complex interacting human and natural systems (Lyall et al. 2014). In this paper, the AAI framework is proposed for understanding and managing the dynamic heterogeneity inherent in very large transdisciplinary projects. Attending to project-wide AAI facilitates tracking team development, quantifying or otherwise measuring team dynamics, and actively encouraging flexibility in response to emerging needs, opportunities, and changes in understanding of the system. Tracking within-boundary and cross-boundary knowledge is a critical next step toward realizing a systems approach (Hammond and Dube 2012) and can lead to disciplinary and transdisciplinary strategies that increase concrete understanding about connections within and between systems. Our experiences with three large collaborative projects addressing climate change and agriculture highlight the power of understanding project architecture as an adaptively managed, dynamic framework with (1) goal-oriented structures, (2) disciplinary and cross-disciplinary components, (3) mechanisms to connect, (4) monitoring and adaptation processes, (5) defined boundaries with flexibility, and (6) awareness of project AAI by participants. This framework promotes innovation, promotes continuous adaption of the platforms used to construct new knowledge, and helps move scientific findings into real-world applications. The intent is to strengthen capacity to better connect theory, data, and reality as we strive to solve important societal problems. 
Responses to this article can be read online at: http://www.ecologyandsociety.org/issues/responses. $\mathrm{php/7788}$

\section{Acknowledgments:}

This research is part of three regional collaborative projects funded by the U.S. Department of Agriculture-National Institute for Food and Agriculture (USDA-NIFA): Award \#2011-68002-30190, Cropping Systems Coordinated Agricultural Project: Climate Change, Mitigation, and Adaptation in Corn-based Cropping Systems (CSCAP; http://www.sustainablecorn.org); Award \#2011-68002-30191, Pacific Northwest Regional Approaches to Climate Change (REACCH-PNA; http://www.reachpna.org); and Award \#2011-68002-30185, Pine Integrated Network: Education, Mitigation, and Adaptation project (PINEMAP; http://www. pinemap.org).

\section{LITERATURE CITED}

Arbuckle, J. G., J. Hobbs, A. Loy, L. Wright Morton, L. S. Prokopy, and J. Tyndall. 2014. Understanding Corn Belt farmer perspectives on climate change to inform engagement strategies for adaptation and mitigation. Journal Soil Water Conservation 69(6):505-516. http://dx.doi.org/10.2489/jswc.69.6.505

Arbuckle, J. G., L. Wright Morton, and J. Hobbs. 2013. Trust, beliefs, and perceived risk as determinants of farmer support for adaptive and mitigative responses to climate change. Environment and Behavior 47(2):205-234. http://dx.doi.org/10.1177/0013916513503832

Bammer, G. 2013. Disciplining interdisciplinarity: integration and implementation sciences for research in complex real-world problems. Australian National University Press, Canberra, Australia.

Bazarova, N. N., and J. B. Walther. 2009. Attributions in virtual groups: distances and behavioral variations in computermediated discussions. Small Group Research 40:138-162. http:// dx.doi.org/10.1177/1046496408328490

Beachy R. N. 2010. Science and sustainability: the emerging consensus. BioScience 60:406-407. http://dx.doi.org/10.1525/ bio.2010.60.6.2

Bergmann, M, T. Jahn, T. Knoblock, W. Krohn, C. Pohl, and E. Schramm. 2012. Methods for transdisciplinary research: a primer for practice. Campus Verlag, Frankfurt, Germany.

Bierly, E. W. 1988. The world climate program: collaboration and communication on a global scale. Annals of the American Academy of Political and Social Science 495:106-116. http://dx. doi.org/10.1177/0002716288495001010

Blackwell, A. F., and D. A. Good. 2008. Languages of innovation. Pages 127-138 in H. Crawford, editor. Artistic bedfellows: histories, theories and conversations in collaborative art practices. University Press of America, Lanham, Maryland, USA.

Christensen, N. L., A. Bartuska, J. H. Brown, S. Carpenter, C. D’Antonio, R. Francis, J. F. Franklin, J. A. MacMahon, R. F. Noss, D. J. Parsons, C.H. Peterson, M. G. Turner, and R. G. Woodmansee. 1996. The report of the Ecological Society of
America Committee on the scientific basis for ecosystem management. Ecological Applications. 6:665-691. http://dx.doi. org/10.2307/2269460

Collins, S. L., S. R. Carpenter, S. M. Swinton, D. E. Orenstein, D. L. Childers, T. L. Gragson, N. B. Grimm, J. M. Grove, S. L. Harlan, J. P. Kaye, A. K. Knapp, G. P. Kofinas, J. J. Magnuson, W. H. McDowell, J. M. Melack, L. A. Ogden, G. P. Robertson, M. D. Smith, and A. C. Whitmer. 2011. An integrated conceptual framework for long-term social-ecological research. Frontiers in Ecology and the Environment 9:351-357. http://dx.doi. org/10.1890/100068

Cooke, N. J., and M. L. Hilton, editors, Committee on the Science of Team Science, Board on Behavioral, Cognitive, and Sensory Sciences, Division of Behavioral and Social Sciences and Education, National Research Council. 2015. Enhancing the effectiveness of team science. The National Academies Press, Washington, DC, USA.

Cornell, S. E., and J. Parker. 2013. Rising to the synthesis challenge in large-program interdisciplinary science: the QUEST experience. Pages 121-147 in M. O'Rourke, S. Crowley, S. Eigenbrode, and J. D. Wulfhorst, editors. Enhancing communication and collaboration in interdisciplinary research. Sage, Thousand Oaks, California, USA.

Crowley, S., S. D. Eigenbrode, M. O'Rourke, and J. D. Wulfhorst. 2010. Cross-disciplinary localization: a philosophical approach. Web Only. MultiLingual. [online] URL: http://www.multilingual. com/downloads/114LCDR.pdf

Dietz, T. 2013. Bringing values and deliberation to science communication. Proceedings of the National Academy of Sciences of the United States of America 110:14081-14087. http://dx.doi. org/10.1073/pnas.1212740110

Eigenbrode, S. D., M. O’Rourke, J. D. Wulfhorst, D. M. Althoff, C. S. Goldberg, K. Merrill, W. Morse, M. Nielsen-Pincus, J. Stephens, L. Winowiecki, and N. A. Bosque-Pérez. 2007. Employing philosophical dialogue in collaborative science. BioScience 57:55-64. http://dx.doi.org/10.1641/B570109

Eigenbrode, S. D., L. Wright Morton, and T. A. Martin. 2014. Big interdisciplinarity to address climate change and agriculture: lessons from three USDA Coordinated Agricultural Projects. Journal of Soil and Water Conservation 69(6):170A-175A. http:// dx.doi.org/10.2489/jswc.69.6.170A

Evans, J. S. 1991. Strategic flexibility for high technology manoeuvres: a conceptual framework. Journal of Management Studies 28:69-89. http://dx.doi.org/10.1111/j.1467-6486.1991. $\underline{\text { tb00271.x }}$

Folke, C., T. Hahn, P. Olsson, and J. Norberg. 2005. Adaptive governance of social-ecological systems. Annual Review of Environment and Resources 30:441-473. http://dx.doi.org/10.1146/ annurev.energy.30.050504.144511

Fox, T. R., E. J. Jokela, and H. L. Allen. 2007. The development of pine plantation silviculture in the southern United States. Journal of Forestry 105:337-347.

Hackett, E. J., J. N. Parker, D. Conz, D. Rhoten, and A. Parker. 2008. Ecology transformed: the National Center for Ecological Analysis and Synthesis and the changing patterns of ecological 
research. Pages 277-296 in G. Olson, A. Zimmerman, and N. Box, editors. Scientific collaboration on the Internet. MIT Press, Cambridge, Massachusetts, USA. http://dx.doi.org/10.7551/ mitpress/9780262151207.003.0016

Hammond, R. A., and L. Dube. 2012. A systems science perspective and transdisciplinary models for food and nutrition security. Proceedings of the National Academy of Sciences of the United States of America 109:12356-12363. http://dx.doi. org/10.1073/pnas.0913003109

Hampton, S. E., and J. N. Parker. 2011. Collaboration and productivity in scientific synthesis. BioScience 61:900-910. http:// dx.doi.org/10.1525/bio.2011.61.11.9

Holling, C. S. 1978. Adaptive environmental assessment and management. John Wiley and Sons, Hoboken, New Jersey, USA.

Innes, J. E. 1994. Knowledge and public policy: the search for meaningful indicators. Transaction, London, UK.

Jackson, L., M. van Noordwijk, J. Bengtsson, W. Foster, L. Lipper, M. Pulleman, M. Said, J. Snaddon, and R. Vodouhe. 2010. Biodiversity and agricultural sustainability: from assessment to adaptive management. Current Opinion in Environmental Sustainability 2:80-87. http://dx.doi.org/10.1016/j.cosust.2010.02.007

Johnson, S. 2010. Where good ideas come from: the natural history of innovation. Riverhead, New York, New York, USA.

Johnson, S. K., K. Bettenhausen, and E. Gibbons. 2009. Realities of working in virtual teams: affective and attitudinal outcomes of using computer-mediated communication. Small Group Research 40:623-649. http://dx.doi.org/10.1177/1046496409346448

Klein, J. T. 2012. Research integration: a comparative knowledge base. Pages 283-298 in A. F. Repko, W. H. Newell, and R. Szostak, editors. Interdisciplinary research. Sage, Thousand Oaks, California, USA. http://dx.doi.org/10.4135/9781483349541.n10

Klein, J. T. 2014. Discourses of transdiciplinarity: looking back to the future. Futures 63:68-74. http://dx.doi.org/10.1016/j. futures.2014.08.008

Lubell, M., V. Hillis, and M. Hoffman. 2011. Innovation, cooperation, and the perceived benefits and costs of sustainable agriculture practices. Ecology and Society 16(4): 23. http://dx.doi. org/10.5751/ES-04389-160423

Lyall, C., L. Meagher, and A. Bruce. 2014. A rose by any other name? Transdisciplinarity in the context of UK research policy. Futures 65:150-162. http://dx.doi.org/10.1016/j.futures.2014.08.009

Mattessich, P., and B. R. Monsey. 1992. Collaboration: what makes it work: a review of research literature on factors influencing successful collaboration. Amherst H. Wilder Foundation, St. Paul, Minnesota, USA.

Max-Neef, M. A. 2005. Foundations of transdisciplinarity. Ecological Economics 53:5-16. $\quad$ http://dx.doi.org/10.1016/j. ecolecon.2005.01.014

McComb, S. A., S. G. Green, and W. D. Compton. 2007. Team flexibility's relationship to staffing and performance in complex projects: an empirical analysis. Journal of Engineering and Technology Management 24:293-313. http://dx. doi.org/10.1016/j. jengtecman.2007.09.004
National Research Council (NRC). 2010. Adapting to the impacts of climate change. The National Academies Press, Washington, D.C., USA.

O'Rourke, M., S. Crowley, S. D. Eigenbrode, and J. D. Wulfhorst, editors. 2013. Enhancing communication \& collaboration in interdisciplinary research. Sage, Thousand Oaks, California, USA.

Palmer, M. A. 2012. Socioenvironmental sustainability and actionable science. BioScience 62:5-6. http://dx.doi.org/10.1525/ bio.2012.62.1.2

Pennington, D. D. 2008. Cross-disciplinary collaboration and learning. Ecology and Society 13(2): 8. [online] URL: http://www. ecologyandsociety.org/vol13/iss2/art8/

Pielke, R. A., Jr. 2007. The honest broker: making sense of science in policy and politics. Cambridge University Press, Cambridge, UK. http://dx.doi.org/10.1017/cbo9780511818110

Pohl, C., L. van Kerkhoff, G. H. Hadorn, and G. Bammer. $2008 a$. Integration. Pages 411-424 in G. H. Hadorn, H. Hoffmann-Riem, S. Biber-Klemm, W. Grossenbacher-Mansuy, D. Joye, C. Pohl, U. Wiesmann, and E. Zemp, editors. Handbook of transdisciplinary research. Springer, New York, New York, USA. http://dx.doi. org/10.1007/978-1-4020-6699-3 27

Pohl, C., and G. H. Hadorn. 2008b. Core terms in transdisciplinary research. Pages 427-432 in G. H. Hadorn, H. Hoffmann-Riem, S. Biber-Klemm, W. Grossenbacher-Mansuy, D. Joye, C. Pohl, U. Wiesmann, and E. Zemp, editors. Handbook of transdisciplinary research. Springer, New York, New York, USA. http://dx.doi.org/10.1007/978-1-4020-6699-3 28

Prokopy, L., L. Wright Morton, J. G. Arbuckle, A. Wilke, and A. Mase. 2015. Agricultural stakeholder views on climate change: implications for conducting research and outreach. Bulletin of Atmospheric Meteorological Society. http://dx.doi.org/10.1175/ BAMS-D-13-00172.1

Pryor, S. C. 2013. Climate change in the Midwest: impacts, risks, vulnerability, and adaptation. Indiana University Press, Bloomington, Indiana, USA.

Reganold, J. P., D. Jackson-Smith, S. S. Batie, R. R. Harwood, J. L. Kornegay, D. Bucks, C. B. Flora, J. C. Hanson, W. A. Jury, D. Meyer, A. Schumacher, Jr., H. Sehmsdorf, C. Shennan, L. A. Thrupp, and P. Willis. 2011. Transforming U.S. agriculture. Science 332:670-671. http://dx.doi.org/10.1126/science.1202462

Rhoten, D. 2003. A multimethod analysis of social and technical conditions for interdisciplinary collaboration. Report No. BCS 0129573. National Science Foundation, Arlington, Virginia, USA.

Rist, L., B. M. Campbell, and P. Frost. 2013. Adaptive management: where are we now? Environmental Conservation 40:5-18. http://dx.doi.org/10.1017/S0376892912000240

Robertson, G. P., and S. M. Swinton. 2005. Reconciling agricultural productivity and environmental integrity: a grand challenge for agriculture. Frontiers in Ecology and the Environment 3:38-46. http://dx.doi.org/10.1890/1540-9295(2005)003[0038:RAPAEI] 2.0.CO;2 
Rubin, K. H., and D. Fornari. 2011. Multidisciplinary collaborations in mid-ocean ridge research. EOS Transactions of the American Geophysical Union 92:141-142. http://dx.doi. org/10.1029/2011EO170002

Schauppenlehner-Kloyber, E., and M. Penker. 2015. Managing group processes in transdisciplinary future studies: how to facilitate social learning and capacity building for self-organised action towards sustainable urban development? Futures 65:57-71. http://dx.doi.org/10.1016/j.futures.2014.08.012

Shaman, J., S. Solomon, R. R. Colwell, and C. B. Field. 2013. Fostering advances in interdisciplinary climate science. Proceedings of the National Academy of Sciences of the United States of America 110(suppl 1):3653-3656. http://dx.doi. org/10.1073/pnas.1301104110

Sharp, P. A., and R. Langer. 2011. Promoting convergence in biomedical science. Science 333:527. http://dx.doi.org/10.1126/ science. 1205008

Slovic, P. 2000. The perception of risk. Earthscan, Sterling, Virginia, USA.

Stokols, D., K. L. Hall, B. K. Taylor, and R. P. Moser. 2008a. The science of team science- overview of the field and introduction to the supplement. American Journal of Preventive Medicine 35: S77-S89. http://dx.doi.org/10.1016/j.amepre.2008.05.002

Stokols, D., S. Misra, R. P. Moser, K. L. Hall, and B. K. Taylor. 2008b. The ecology of team science-understanding contextual influences on transdisciplinary collaboration. American Journal of Preventive Medicine 35:S96-S115. http://dx.doi.org/10.1016/j. amepre.2008.05.003

Strijbos, S. 2010. Systems thinking. Pages 453-470 in R. Frodeman, J. T. Klein, and C. Mitcham, editors. Oxford handbook of interdisciplinarity. Oxford University Press, New York, New York, USA.

Tress, G., B. Tress, and G. Fry. 2004. Clarifying integrative research concepts in landscape ecology. Landscape Ecology 20:479-493. http://dx.doi.org/10.1007/s10980-004-3290-4

Troster, C., A. Mehra, and D. van Knippenberg. 2014. Structuring for team success: the interactive effects of network structure and cultural diversity on team potency and performance. Organizational Behavior and Human Decision Processes. 124:245-255.

Walters, C. J. 1986. Adaptive management of renewable resources. Macmillan, London, UK.

Walthall, C. L., J. Hatfield, P. Backlund, L. Lengnick, E. Marshall, M. Walsh, S. Adkins, M. Aillery, E. A. Ainsworth, C. Ammann, et al. 2012. Climate change and agriculture in the United States: effects and adaptation. USDA Technical Bulletin 1935. U.S. Department of Agriculture, Washington, D.C., USA.

Wasson, C. 2012. Virtual organizations. Pages 346-361 in D. D. Caulkins and A. T. Jordan, editors. A companion to organizational anthropology. Wiley-Blackwell, Hoboken, New Jersey, USA.

Wheatley, M. 1999. Leadership and the new science. BerrettKoehler, San Francisco, California, USA.
Wright Morton, L., and S. S. Brown, editors. 2011. Pathways for getting to better water quality: the citizen effect. Springer, New York, New York, USA. http://dx.doi.org/10.1007/978-1-4419-7282-8 